\title{
CONTEXTOS DA PRECARIZAÇÃO DOCENTE NA EDUCAÇÃO BRASILEIRA
}

\author{
Abilia Ana de Castro Netal \\ Juliana da Silva Moura² \\ Berta Leni Costa Cardoso 3 \\ Claudio Pinto Nunes 4
}

\section{RESUMO}

Este artigo objetiva discutir os contextos da precarização docente na educação brasileira. Para isso, foram investigadas duas docentes que atuam na educação básica (pública e privada) em um município na região sudoeste da Bahia. As docentes participaram de uma entrevista semiestruturada contendo eixos norteadores relativos à precarização do trabalho docente. Com efeito, os depoimentos das participantes em consonância com os achados da literatura, denota a precarização do trabalho docente na educação brasileira, materializada, sobretudo, pelo modo em que o trabalho é organizado nos moldes do capitalismo contemporâneo. Esses depoimentos evidenciam que o fenômeno da precarização afeta consideravelmente o seu lócus de trabalho. Não obstante marcado pela flexibilização, intensificação, descumprimento da legislação educacional, a

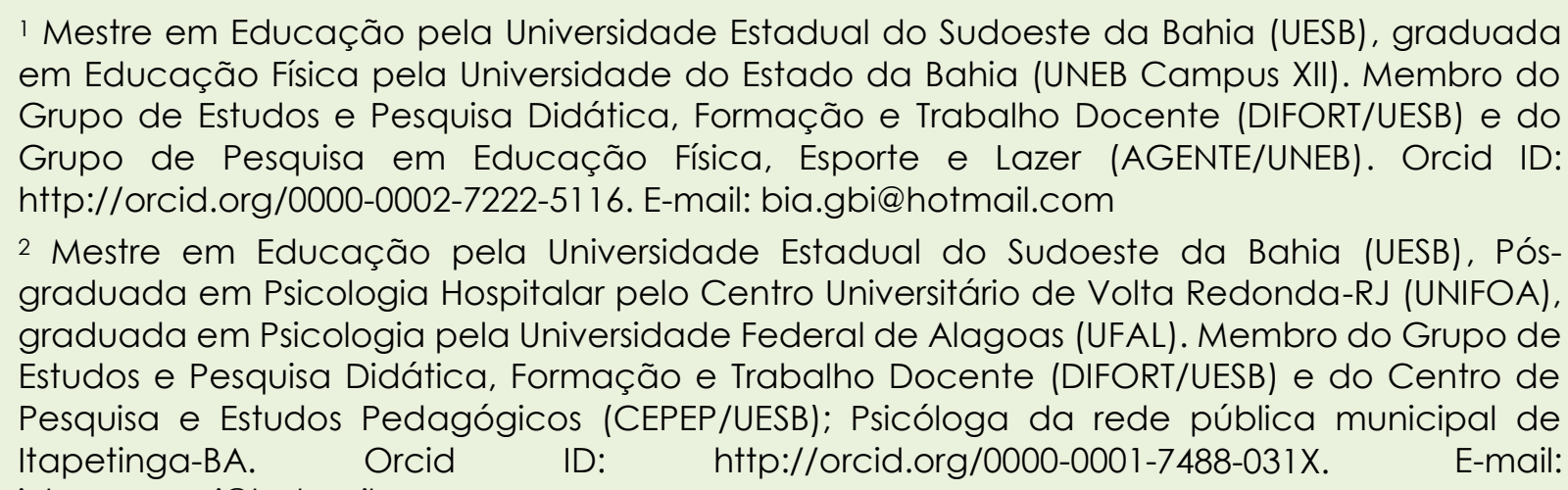
julymourapsi@hotmail.com

3 Doutora em Educação Física pela Universidade Católica de Brasília (UCB/Brasília), pósdoutora em Educação pela Universidade Estadual do Sudoeste da Bahia. É professora adjunta da Universidade do Estado da Bahia. Membro do Grupo de Estudos e Pesquisa Didática, Formação e Trabalho Docente (DIFORT/UESB) e da Linha de Estudo Pesquisa e Extensão em Atividade Física (LEPEAF). Orcid ID: http://orcid.org/0000-0001-7697-0423. E-mail: bcardoso@uneb.br

${ }^{4}$ Doutor em Educação, pela Universidade Federal do Rio Grande do Norte (UFRN), pós-doutor em Educação, pela Universidade Federal de Minhas Gerais (UFMG). É membro do corpo docente do Programa de Pós-Graduação em Educação da Universidade Estadual do Sudoeste da Bahia (UESB). Orcid ID: http://orcid.org/0000-0003-1514-6961. E-mail: claudionunesba@hotmail.com 
flexibilização das formas contratuais, a perda de autonomia sobre o processo de trabalho, a responsabilização, a competitividade, a desprofissionalização, a degradação, a educação e o labor da classe trabalhadora a serviço do capital, o sofrimento psíquico, o adoecimento e alienação dessa categoria profissional. Esperase que esta investigação contribua tanto para o debate acadêmico como para a luta política e sindical dos trabalhadores contra a exploração capitalista e suas consequências para as condições de vida e trabalho daqueles que precisam vender sua força de trabalho para se reproduzir.

Palavras-chave: Precarização. Trabalho docente. Neoliberalismo.

\title{
CONTEXTS OF TEACHER PRECARIOUSNESS IN BRAZILIAN EDUCATION
}

\begin{abstract}
This article aims to discuss the contexts of teacher precariousness in Brazilian education. For this, two teachers who work in basic education (public and private) in a municipality in the Southwest region of Bahia were investigated. The teachers participated in a semi-structured interview containing guidelines related to the precariousness of the teaching work. Indeed, the testimonies of the participants in line with the findings of the literature, denotes the precariousness of teaching work in Brazilian education, materialized, above all, by the way in which work is organized along the lines of contemporary capitalism. These testimonies show that the precariousness phenomenon considerably affects their place of work. Notwithstanding the flexibility, intensification, non-compliance with educational legislation, the flexibility of contractual forms, the loss of autonomy over the work process, accountability, competitiveness, deprofessionalization, degradation, education and the work of the working class a capital service, psychological suffering, illness and alienation of this professional category. This investigation is expected to contribute both to the academic debate and to the workers' political and union struggle against capitalist exploration and its consequences for the living and working conditions of those who need to sell their labor power to reproduce.
\end{abstract}

Keywords: Precariousness. Teaching Work. Neoliberalism.

\section{CONTEXTOS DE PRECARIEDAD DOCENTE EN LA EDUCACIÓN BRASILEÑA}

\section{RESUMEN}

Este artículo tiene como objetivo discutir los contextos de precariedad docente en la educación brasileña. Para esto, se investigaron dos docentes que trabajan en educación básica (pública y privada) en un municipio de la región suroeste de Bahía. Los docentes participaron en una entrevista semiestructurada que contiene pautas relacionadas con la precariedad del trabajo docente. De hecho, los testimonios de 
los participantes en línea con los hallazgos de la literatura denotan la precariedad del trabajo docente en la educación brasileña, materializado, sobre todo, por la forma en que el trabajo se organiza de acuerdo con las líneas del capitalismo contemporáneo. Estos testimonios muestran que el fenómeno de la precariedad afecta considerablemente su lugar de trabajo. A pesar de la flexibilidad, la intensificación, el incumplimiento de la legislación educativa, la flexibilidad de las formas contractuales, la pérdida de autonomía sobre el proceso de trabajo, la rendición de cuentas, la competitividad, la desprofesionalización, la degradación, la educación y el trabajo de la clase trabajadora a servicio de capital, sufrimiento psicológico, enfermedad y alienación de esta categoría profesional. Se espera que esta investigación contribuya tanto al debate académico como a la lucha política y sindical de los trabajadores contra la exploración capitalista y sus consecuencias para las condiciones de vida y de trabajo de aquellos que necesitan vender su fuerza laboral para reproducirse.

Palabras clave: Precariedad. Trabajo Docente. Neoliberalismo.

\section{INTRODUÇÃO}

Este artigo objetiva discutir os contextos da precarização docente na educação brasileira. Para tanto, foram investigadas duas docentes que atuam na educação básica de uma cidade localizada no sudoeste da Bahia, uma ligada à rede pública estadual e, a segunda, ligada à rede privada. As docentes participaram de uma entrevista semiestruturada contendo eixos norteadores relativos à precarização do trabalho docente - instrumento inspirado pelo estudo de Piovezan (2017).

Inicialmente foi estabelecido um contato com as professoras, o qual foi apresentado o estudo, seus fins, bem como o Termo de Consentimento Livre e Esclarecido - TCLE. As condições para a aplicação do instrumento foram acordadas com as participantes. As informações foram coletadas sem custos para as entrevistadas e os dados de identificação mantidos em sigilo, como forma de preservação da integridade moral das participantes, atribuindo para isso, nomes fictícios, quando necessário registro, cujos interesses se voltam, excepcionalmente, para a concretização da pesquisa.

Para isso assumimos, numa perspectiva materialista dialética e pela análise e interpretação das referencias sobre o tema, a proposta de entender como a precarização do trabalho docente se materializa na educação 
brasileira, fundada no ideário neoliberal, mediado pelas demandas de mercado, consegue manter a condição alienante e degradante do trabalho docente. A partir de uma análise crítica e dialética sobre o objeto em tela, este artigo visa contribuir para a valorização do ser/estar docente, enquanto instrumento de posicionamento político e ideológico contra hegemônico, para retirada do professor de seu estado de resignação e exploração, conduzindo-o para uma concepção emancipadora.

\section{A PRECARIZAÇÃO DO TRABALHO DOCENTE}

Subsistimos em uma sociedade regida pelo modo de produção capitalista. Este se refaz e se rearranja ciclicamente. Toda vez que ocorre uma tendencial queda das taxas de lucro, instaura-se um cenário de crise do capitalismo. A cada crise, o capitalismo se reinventa e busca novas formas para manter a sua hegemonia.

O capital é permeado por constantes crises sem, no entanto, perder sua característica essencial que é a acumulação através da expropriação do trabalho, da extração da mais-valia e da manutenção da propriedade privada dos meios de produção, ocasionando, portanto, a consequente manutenção de uma sociedade organizada em classes sociais: a dos detentores dos meios de produção, do controle do Estado e, portanto do poder; e, outra subalterna, possuidora apenas da sua própria força de trabalho e de onde a primeira extrai por meio da exploração e controle do trabalho sua condição privilegiada (MARX, 1988).

São nessas crises que o capitalismo se fortalece e retoma seu desenvolvimento, buscando, portanto, novas formas de se reestruturar e superar-se. A este respeito, esclarece Frigotto (1995, p. 62): "a crise é um elemento constituinte, estrutural, do movimento cíclico da acumulação capitalista, assumindo formas específicas que variam de intensidade no tempo e no espaço". O neoliberalismo surge, nessa conjuntura, como estratégia para salvar a economia capitalista no período da crise da década de 1970 (RODRIGUES, 2017). No tocante ao neoliberalismo, Moura et al. (2019, p. 02-03) salientam: 
As mudanças nos processos de produção capitalista são constantes e atravessam fases cíclicas que alternam entre declínio e ascensão do sistema. No bojo dessas mudanças, vimos emergir a ideologia neoliberal que traz a prerrogativa do Estado-mínimo, ou seja, a baixa atuação do poder público para as demandas sociais, controle dos gastos públicos, desregulamentação dos direitos trabalhistas, reformas fiscais e investimentos para tornar a economia forte e promover o equilíbrio monetário.

O neoliberalismo consiste, portanto, em uma roupagem/versão contemporânea do capitalismo. Contribuindo com esta perspectiva, Nozaki e Andrade (2011) reafirmam que o neoliberalismo é uma:

[...] tentativa de salvar a essência do sistema que é a exploração e expropriação do trabalho, novas ideologias e receitas políticas, econômicas e sociais são postas à prova. Surgem, portanto, as orientações orquestradas pelas classes dominantes e seus sustentáculos na classe política, grande mídia e instituições do próprio Estado de Direito (NOZAKl; ANDRADE, 2011, p. 137).

Silva (2014) salienta que os pressupostos do pensamento neoliberal se fazem presentes nas reformulações das políticas públicas de cunho social, notadamente, a educação. Consequentemente, isto implica afirmar que a tônica e predomínio do neoliberalismo vão se fazer presentes também no trabalho docente e, a partir da sua ascensão em solo brasileiro - sobretudo na década de 1990, intensificou o fenômeno da precarização do trabalho docente. O estudo em tela objetiva analisar este fenômeno a partir do olhar dos sujeitos que estão diretamente envolvidos neste processo, os docentes.

Segundo Piovezan (2017), o termo trabalho precário é mencionado pela literatura acadêmica para caracterizar as novas condições de trabalho estabelecidas após a crise na década de 1970. Nesta perspectiva, conforme Rosenfield (2011, p. 264), o trabalho precário é o "[...] trabalho socialmente empobrecido, desqualificado, informal, temporário e inseguro, a noção de precarização aqui adotada remete a um processo social de institucionalização da instabilidade". Druck (2011, p. 41), por seu turno, estabelece que o trabalho precário está presente "[...] nas formas de inserção 
e de contrato, na informalidade, na terceirização, na desregulação e flexibilização da legislação trabalhista, no desemprego, [...] na perda salarial, na fragilidade dos sindicatos". Em linhas gerais, nota-se que o fenômeno da precarização do trabalho é caracterizado, sobretudo, pela corrosão dos direitos trabalhistas.

No Brasil, o fenômeno da precarização do trabalho ampliou-se, notadamente, nos anos de 1990 e 2000, em função das conquistas trabalhistas tardias no país e do avanço de políticas neoliberais. A precarização do trabalho atingiu diversas categorias de trabalhadores, desde aqueles do setor industrial, do setor de serviços e as categorias conhecidas por realizarem um trabalho intelectual, entre as quais, a classe trabalhadora docente (PIOVEZAN, 2017).

De acordo com Piovezan (2017) os principais elementos constitutivos que caracterizam o fenômeno da precarização do trabalho docente, tendo em vista as novas tendências produtivas, financeiras e políticas desenvolvidas após os anos de 1970, são: a flexibilização do trabalho; a intensificação do trabalho; a flexibilização nas formas de contratação; o arrocho salarial; a perda do controle sobre o processo de trabalho; e, o aguçamento da alienação.

Com base nos elementos da precarização, direcionamos indagações/provocativas às docentes investigadas. Nesta perspectiva, a professora Letícia - nome fictício escolhido pela primeira participante, inicialmente foi interpelada sobre as funções que executa e se sua formação contemplou todas as exigências do seu ofício profissional. A docente sinaliza que executa distintas tarefas, muitas delas completamente destoantes de sua área de formação, o que fragiliza sobremaneira seu trabalho pedagógico. Assim, ao discutir sobre o fenômeno da precarização do trabalho, Antunes (2009, p. 234) destaca as principais características que o compõe, enfatizando a flexibilização. Nesta perspectiva o autor estabelece: 
Entre as distintas formas de flexibilização - em verdade, precarização - podemos destacar, por exemplo, a salarial, de horário, funcional ou organizativa. A flexibilização pode ser entendida como 'liberdade da empresa' para desempregar trabalhadores; sem penalidades, quando a produção e as vendas diminuem; liberdade, sempre para a empresa, para reduzir o horário de trabalho ou de recorrer a mais horas de trabalho; possibilidade de pagar salários reais mais baixos do que a paridade de trabalho exige; possibilidade de subdividir a jornada de trabalho em dia e semana segundo as conveniências das empresas, mudando os horários e as características do trabalho (por turno, por escala, em tempo parcial, horário flexível etc.); dente outras formas de precarização da força de trabalho.

Como exposto, Antunes (2009) evidencia o fenômemeno da flexilização ao refletir sobre a precariedade do trabalho nos moldes do capitalismo contemporâneo. Contribuindo na mesma perspectiva, Antunes e Praun (2015) complementam:

A flexibilidade ou flexibilização se constitui no contexto atual em uma espécie de síntese ordenadora dos múltiplos fatores que fundamentam as alterações na sociabilidade do capitalismo contemporâneo. Do ponto de vista de seu impacto nas relações de trabalho, a flexibilização se expressa na diminuição drástica das fronteiras entre atividade laboral e espaço da vida privada, no desmonte da legislação trabalhista, nas diferentes formas de contratação da força de trabalho e em sua expressão negada, o desemprego estrutural. Pode ser percebida ainda, no dia a dia da atividade laboral, diante da forte sensação de que o tempo foi comprimido; ou também na clara densificação da jornada de trabalho, na qual todos se desdobram para executar sozinhos o que antes era feito por dois ou mais trabalhadores (ANTUNES; PRAUN, 2015, p. 412).

Licenciada em Pedagogia, Letícia é habilitada para trabalhar com Educação Infantil e Séries Iniciais (Ensino Fundamental I). No entanto, a docente ministra aulas no Ensino Fundamental II e Ensino Médio, com os seguintes componentes curriculares: Filosofia, Sociologia, Artes, História, Língua Portuguesa e Literatura Brasileira - LPLB, Identidade e Cultura em uma unidade escolar da rede pública estadual. Tal fenômeno corrobora com os 
apontamentos de Santos (2014) ao discutir que por influência do ideário neoliberal, os professores são cobrados a responder questões cujas respostas estão muito além da sua formação. A docente demostrou insegurança no trato com os componentes curriculares apontados, alegando não serem de sua competência acadêmica.

Atualmente a docente trabalha sob Regime Especial de Direito Administrativo - REDA, perfazendo carga horária semanal de 20 horas. A docente esclarece:

Trabalhei nesta escola em um primeiro período pelo regime REDA. Após seleção pública. Antes de o período contratual vencer, fui substituída por uma professora efetiva, ficando excedente e esquecida por dois anos.

Atualmente trabalho na mesma escola através de contrato temporário e tempo indefinido para suprir uma carência imediata da escola. Iniciei em novembro de 2018 e, até a presente data, não recebi pagamento salarial.

Meus direitos não são efetivamente respeitados. Um verdadeiro descaso!

O interesse dos governantes em inserir, excessivamente, docentes contratados em caráter temporário nas escolas é de reduzir gastos, pois o professor contratado recebe menos (LETÍCIA - REDE PÚBLICA).

Destarte, Piovezan (2017) aponta que a flexibilização das formas de contratação contribui para a ampliação de dois fenômenos: 1) a inserção excessiva de docentes contratados em caráter temporário nas escolas, haja vista que os poderes públicos expandem essa forma flexível de contratação com a finalidade de reduzir gastos, como explicitado na fala da docente; e, 2) o aumento na distribuição de aulas para cada docente, suscitando a intensificação do trabalho. Além da instabilidade financeira, o professor eventual não estabelece vínculo pedagógico estável com a escola, com os professores e as turmas nas quais lecionam, já que muitos vivenciam a itinerância de uma unidade escolar para outra. A flexibilização na admissão dos docentes eventuais expõe, também, a desprofissionalização dos atuantes (PIOVEZAN, 2017). 
Para Matias e Abib (2007), o Estado, sob influência neoliberal, retira e diminui benefícios e direitos dos trabalhadores, precarizando, dessa forma, seus vínculos e aumentando a carga de trabalho. A flexibilização do trabalho, de acordo com Franco, Druck e Seligmann-Silva (2010), diluiu a nítida separação entre os incluídos e os excluídos, causando uma desestabilização no mundo do trabalho, atingindo, hoje, todos os que necessitam do trabalho para sobreviver. Desde a década de 1980, essa desestabilização, caracterizada por demissões em massa, teve como consequência a admissão de trabalhadores por meio de formas precarizadas de contratação, por exemplo, os contratos por tempo determinado (FRANCO; DRUCK; SELIGMANN-SILVA, 2010).

Franco, Druck e Seligmann-Silva (2010) complementam trazendo as dimensões desse processo: a primeira diz respeito aos vínculos de trabalho e relações contratuais (perda dos direitos trabalhistas); a segunda é referente à organização e às condições de trabalho (ritmo intenso de trabalho, pressão, competitividade); a terceira está relacionada com a precarização da saúde dos trabalhadores; a quarta diz respeito à fragilização do reconhecimento social, da valorização simbólica e do processo de construção das identidades individual e coletiva; e a quinta se refere à representação e à organização coletiva (sindical). Nesta perspectiva, Brito, Prado e Nunes (2017, p. 173) preconizam:

No Brasil, tem-se acompanhado um movimento de dilatação das atividades do professor a partir da desregulação e da redefinição das suas atividades laborais, consequentemente, isso tem contribuído para a precarização das condições de trabalho docente.

As novas atribuições e a urgência em atender as demandas provocam a intensificação do trabalho e pode trazer graves consequências à saúde do professor. Dentre os problemas mais comuns estão os distúrbios vocais, em decorrência do uso excessivo da voz na sala de aula.

A extensa carga horária assumida por muitos profissionais além de agravar os distúrbios vocais, resulta em cansaço físico e mental. Geralmente, os docentes costumam apresentar quadros de depressão, ansiedade, estresse, nervosismo, além 
de sintomas físicos como dores e cansaço. Esses sintomas surgem em decorrência de diversos fatores, e em alguns casos, é necessário o afastamento dos professores da sala de aula.

No Brasil, outro fator que impacta as condições de trabalho docente está relacionado à remuneração. Além dos baixos salários da categoria, existe também uma variação salarial conforme os sistemas de ensino, as regiões do país e o vínculo empregatício (efetivo ou temporário). Esse quadro se caracteriza como um processo de precarização e desvalorização da profissão.

Na atual conjuntura, os professores se encontram imersos em um cenário político de expropriação dos seus direitos e desvalorização da sua carreira que provoca sentimentos de angústia, frustração e insatisfação com a profissão.

Diante desse cenário, faz-se urgente repensar algumas questões que envolvem a docência, como os tempos pedagógicos e formativos, os espaços e os recursos necessários para realizar a ação pedagógica qualificada, valorização da atividade docente, com vistas à adoção de uma política permanente de estímulo à profissionalização, jornada única, formação continuada, melhoria da remuneração e garantia de condições dignas de trabalho.

A professora Ana - nome fictício escolhido pela segunda participante, desenvolve seu ofício na rede privada de ensino. A docente sinaliza:

Atualmente me dedico exclusivamente a cinco turmas do ensino fundamental II em uma instituição de ensino privada. Sou formada pela Universidade do Estado da Bahia, no curso de licenciatura plena em geografia. Atuo em minha área de formação e tenho muito orgulho e satisfação pelo meu trabalho.

Me sinto privilegiada por lecionar na minha área de formação, pois, conheço a realidade da escola brasileira e sei quantos professores são remanejados para uma sala de aula lotada de alunos lecionando uma disciplina que não domina (por não ser sua área de formação). As dificuldades são grandes tanto para aquele que ministra a aula, como para o educando que terá seu processo de aprendizagem abalado (ANA - REDE PRIVADA).

Nota-se um distanciamento entre as falas das participantes. Letícia ministra aulas na rede pública estadual com componentes curriculares destoantes de sua área de formação acadêmica, o que compromete sobremaneira seu desenvolvimento profissional docente e o processo de ensino aprendizagem dos educandos. Ana, por seu turno, ministra o 
componente curricular no qual foi academicamente formada, sinalizando segurança e satisfação pelo trabalho desenvolvido.

Em relação ao tempo destinado aos estudos, a docente Letícia veemente afirma: "Pouquíssimo tempo! Lecionando um conjunto de disciplinas fica mais complicado ainda, o estudo acaba se tornando algo cansativo, penoso e, por conseguinte, sem produção" (LETíCIA - REDE PÚBLICA). O posicionamento da docente corrobora com as reflexões de Piovezan (2017), pois, com o aumento excessivo de atividades a serem desenvolvidas, os professores não conseguem cumprir uma das principais necessidades da sua profissão, isto é, ser um estudioso da sua área (PIOVEZAN, 2017). Segundo Santos (2012, p. 66) essa atividade tão necessária para os docentes foi comprometida, afinal, lecionando em média 40 horas semanais "[...] que tempo pedagógico se reserva à reflexão, à leitura do mundo, numa organização do trabalho escolar que impõe um ritmo fabril ao docente?".

Ao ser indagada acerca da intensificação do trabalho docente, Letícia aponta que ministrar muitas aulas, trabalhar em diferentes escolas e com um número excessivo de alunos compromete sobremaneira o trabalho desenvolvido pelo professor. A docente complementa:

Leciono 16 aulas semanais, escolhi trabalhar assim para não comprometer a minha produtividade. A escola onde trabalho está passando por um processo de reordenamento, em poucos anos será fechada. Com isso, neste ano letivo (2019) perdemos oito turmas.

O turno matutino possui um número maior de alunos, as turmas são lotadas, tornando o trabalho em sala de aula pouco produtivo, pois o professor não dá conta de atender todas as demandas comuns em escolas da rede pública (alunos com necessidades especiais de aprendizagem, desinteresse e indisciplina por parte de alguns alunos, entre outros). Já nos turnos vespertino e noturno as turmas são menores em número de alunos, mas os problemas não deixam de existir (LETíCIA - REDE PÚBLICA).

A docente Ana também aponta os prejuízos e a complexidade em ministrar aulas em salas com um número demasiado de alunos: 
As salas de aulas são cheias de alunos, a turma menor possui 27 alunos (6" "B") e a maior possui 38 (70 "B"). A diferença em ministrar as aulas nas duas turmas é inquestionável, pois, no sexto ano, nota-se uma aula mais tranquila, permitindo um acompanhamento mais eficaz com o aluno de forma individualizada. No sétimo ano, por sua vez, onde o número de alunos é maior, a aula não flui da mesma forma, possuindo características próprias a cada dia, isso significa dizer que a turma se mostra agitada, com comportamentos de indisciplina, indiferença e desinteresse em determinados dias. Percebe-se, assim, a complexidade de uma sala de aula com um número maior de estudantes, no geral, toda a rotina escolar é diferenciada, inclusive a metodologia do professor, essa deve possuir características diferentes para essas salas, seu método de abordagem, segurança ao ministrar as aulas, controle de turma para a indisciplina, pois o professor precisa desenvolver manobras para buscar a atenção de todos, uma vez que os alunos se distraem com facilidade (ANA - REDE PARTICULAR).

Ambas sinalizam uma intensificação do trabalho docente, fenômeno comum nas instituições de ensino brasileiras a partir da década de 1960. Nesta perspectiva, Assunção e Oliveira (2009) discutem sobre os prejuízos da intensificação do trabalho docente, pois, as consequências desse fenômeno não afetam somente a saúde física, mental e pessoal destes profissionais, mas a qualidade do trabalho em si, uma vez que "[...] a intensificação diz respeito não somente à expansão e ao acúmulo de constrangimentos de tempo durante a realização do trabalho, mas também às transformações impingidas à qualidade do serviço, do produto" (ASSUNÇÃO; OLIVEIRA, 2009, p. 354).

Em relação às questões salariais, Letícia aponta para uma completa insatisfação, sobretudo por não receber a aproximadamente quatro meses. Nesta conjuntura, a medida adotada pelo governo federal para determinar o salário dos professores foi à instituição de um piso salarial nacional para o profissional do magistério da educação básica, conforme a Lei $n^{\circ} 11.738$, de 16 de julho de 2008. Apesar do baixo salário instituído pelo piso, diversos Estados brasileiros alegaram a inconstitucionalidade da lei e não a cumpriu integralmente, negligenciando o valor do salário, a jornada de trabalho de 40 horas ou 0 1/3 da carga horária destinada para as atividades extraclasses (PIOVEZAN, 2017). O Ministério da Educação anunciou reajuste de $4,17 \%$ no piso salarial dos professores. Em 2019, o piso salarial esteve fixado em R\$ 
$2.557,74$ (40 horas). Atualmente, o piso nacional do magistério está fixado em $\mathrm{R} \$ 2.886,15$ (40 horas). No entando, em relação ao descumprimento da Lei do Piso, Letícia assevera:

Esse piso é uma verdadeira piada, um descaso em relação aos profissionais da educação. Precisamos de reconhecimento, de incentivo, de salário digno que seja condizente com o nosso exercício profissional e a nossa formação acadêmica (LETíCIA REDE PÚBLICA).

No bojo dessa discussão, a docente Letícia reflete acerca da necessidade de reconhecimento no seio profissional. No tocante a este aspecto, Nogueira e Brasil (2013, p. 105), ao investigarem acerca do lugar do reconhecimento no trabalho docente, preconizam:

[...] a ausência do reconhecimento no trabalho docente é uma importante fonte de mal-estar para o professor. Ter que lidar com a violência no espaço escolar, a precarização do trabalho, a ausência de recursos materiais e humanos e a desvalorização progressiva da profissão, tem comprometido a saúde mental e a qualidade de vida do professor a cada dia, aumentando a dificuldade do seu trabalho.

O professor sofre pelo desejo de reconhecimento, e este sentimento de desesperança soma-se a um certo constrangimento em relação a seus pares, pais e alunos. Essas manifestações de desconforto batem naquilo que é da ordem do insuportável e causa extremo sofrimento. Adoecido pelas condições do cotidiano escolar, precisa perceber que aquilo que foi construído fez algo da ordem do reconhecimento, o que o afastará um pouco do sentimento de desamparo. O docente precisa contar com o reconhecimento dos colegas, pois isso protege sua auto-estima e ajuda a manter sua identidade profissional, além de reforçar os vínculos entre os membros da profissão e seu senso de pertencimento a ela.

Sobre as questões contratuais e salarias, Ana argumenta:

Meu contrato de trabalho foi realizado via assinatura da carteira nacional de trabalho. O salário é pago mediante ponto batido diariamente nos horários de aula, de acordo estabelecido pela coordenação pedagógica. Além de estar baseado na hora aula, são adicionados: atendimento aos pais dos alunos, férias, salário família e $013^{\circ}$ salário. Me sinto assegurada dentro das 
condições trabalhistas e perante a lei do contrato da instituição de ensino particular. Porém, os valores pagos não seguem as normas conforme $\mathrm{o}$ piso salarial profissional do magistério público. O valor é menor.

Minha renda mensal não supre totalmente as minhas necessidades, desta forma, busco algumas atividades extras para complementar a renda mensal familiar (ANA - REDE PRIVADA).

O piso salarial instituído em 2008, teve sua constitucionalidade aprovada em 2011, devendo ser reajustado anualmente e visa, antes de qualquer outro fator, promover a valorização do profissional docente. No Plano Nacional de Educação de 2014 ficou determinado ainda, na meta 17, que o rendimento médio dos profissionais do magistério das redes públicas de educação básica deve ser equiparado até 2020, ao dos demais profissionais com escolaridade equivalente, correspondendo em 2017 (último levantamento) a 74,8\% (BRASIL, 2018). De acordo com a fala das docentes investigadas e com o que está preconizado nestes documentos oficiais, nenhuma das duas docentes usufrui do que está determinada na lei. A primeira por ser funcionária contratada, não tendo vínculo efetivo com a rede pública de educação básica e a segunda por ser integrante da rede particular. Não estando amparadas legalmente, o quadro de precarização mostra-se ainda mais perverso, já o que valor do salário é insuficiente para cobrir suas necessidades básicas tendo que recorrer a outros meios para complementá-la.

Ao serem interpeladas acerca da autonomia sobre seu fazer pedagógico e, quem, efetivamente, controla o trabalho exercido pelos docentes, Letícia afirma que:

A elaboração do currículo, a escolha dos livros utilizados nas salas de aulas e os critérios que determinam as avaliações dos alunos são as principais formas de controle do fazer pedagógico, o que limita a autonomia do professor. É importante ressaltar que dentro da sala de aula existe uma diversidade de indivíduos, cada um com suas particularidades e um único professor para dar conta de todas as demandas. Os critérios de avaliação, o currículo escolar e os livros didáticos, na maioria das vezes, estão bem distantes da realidade escolar pública (LETÍCIA - REDE PÚBLICA). 
Ana corrobora com os apontamentos de Letícia, e enfatiza:

$\mathrm{Na}$ instituição de ensino que trabalho somos orientados pela coordenação pedagógica que, na prática, determina como devemos agir na sala de aula. Essa coordenação "aconselha" como devemos portar, o que falar, como abordar, o que vestir, como avaliar, como corrigir.

A instituição particular tira a autonomia do professor em ministrar suas aulas!

Muitos perdem a autonomia desde a escolha do livro didático, a uma simples atividade desenvolvida no cotidiano escolar (ANA - REDE PARTICULAR).

Os posicionamentos das docentes expressam um fenômeno comum nas escolas brasileiras, à perda do controle sobre o processo de trabalho, outro elemento que constitui o fenômeno da precarização do trabalho docente, somando-se a: intensificação e flexibilização do trabalho, o arrocho salarial e a flexibilização contratual. Segundo Braverman (1987), a divisão do trabalho no sistema de produção capitalista é provocada em razão da separação/cisão entre a concepção e a execução, isto é, de um lado, um grupo de indivíduos que planeja o processo de trabalho e, do outro, um grupo que o executa. Em relação aos docentes, esta categoria de trabalhadores também lida com a segregação entre quem decide e quem realiza as atividades na escola. Um grupo seleto de indivíduos, que compõe um corpo técnico do governo ${ }^{5}$, domina a organização dos programas e de qual forma deve ser executada a gestão e o ensino nas escolas. O outro grupo, formado pelos professores, realiza as atividades na escola e na sala de aula, conforme foi estabelecido pelos órgãos reguladores, cabendo a eles, excepcionalmente, reproduzir as determinações do capital (PIOVENZAN, 2017).

Segundo Piovezan (2017) além do controle do currículo e dos manuais didáticos, as avaliações de larga escalab são atualmente uma das formas

\footnotetext{
${ }^{5}$ Representantes do capital: empresários, editoras de livros, etc.

6 Em relação ao governo federal, as avaliações da educação básica mais importantes são aquelas que compõem o Sistema Nacional de Avaliação da Educação Básica (SAEB) desenvolvida pelo Instituto Nacional de Estudos e Pesquisas Educacionais Anísio Teixeira (INEP): a Prova Brasil ou Avaliação Nacional do Rendimento Escolar (ANRESC); a Avaliação Nacional
} 
mais sofisticadas de controle das escolas por parte das Secretarias de Educação dos Estados e do governo federal (PIOVEZAN, 2017) que, por seu turno, reproduzem os interesses do capital mundial. No que concernem às avaliações externas, as docentes se posicionam:

As avaliações externas devem ser ferramentas para que a escola repense a sua dinâmica de trabalho, uma possibilidade, e não a única. O que avaliar e como avaliar, em minha opinião, deve partir do professor que está na linha de frente com o aluno, que o conhece mais do que as autoridades que estão em suas poltronas definindo o currículo escolar (LETíCIA - REDE PÚBLICA).

[...] Existe uma diferença muito grande entre quem pensa o trabalho docente e quem, de fato, o executa. É preciso um conhecimento íntimo com o interior de uma sala de aula "Iotada" de estudantes, um conhecimento da área e a realidade social de cada escola para depois mencionar algo que aconteça, de fato.

Hoje se questiona muito o trabalho do professor, mas sempre por aqueles que jamais se permitiram estar um dia em uma sala de aula. Jamais se permitiram conhecer a realidade concreta de algumas instituições de ensino (ANA - REDE PRIVADA).

Observamos no discurso da professora Ana que, no contexto escolar, também há uma divisão hierárquica do trabalho. As parcerias firmadas entre o Estado e instituições, entre as quais, empresas privadas, fundações, institutos e Organizações Não-Governamentais (ONG), passaram a atuar na organização de questões educacionais das redes públicas de ensino, interferindo até mesmo na formulação e redefinição dos conteúdos das políticas públicas, na execução de ações e coordenação, monitoramento, de metas e resultados. Esse processo vem redimensionando as relações entre o público e o privado e reorganizando a gestão da educação pública brasileira (PERONI, 2013; 2015).

Nesse contexto, o professor não necessita mais ser um intelectual que possibilita ao aluno o acesso ao conhecimento historicamente elaborado

da Educação Básica (ANEB) e a Avaliação Nacional da Alfabetização (ANA) (PIOVEZAN, 2017). 
pela humanidade, que o auxilia na compreensão de mundo e no desenvolvimento de suas capacidades reflexivas e críticas. Ele necessita, apenas, realizar as atividades propostas externamente pela classe dominante, que não o reconhece como ator fundamental/essencial no processo educativo. Contribuindo com essa perspectiva, Mazzini (2017) ressalta que no capitalismo há uma divisão hierárquica do trabalho. A força de trabalho do homem acabou se transformando em mercadoria, o sujeito ilusoriamente livre, isso porque não possui os meios de produção e o controle sobre o seu processo de trabalho.

A autonomia docente vem sendo comprometida sobremaneira. A escola, a educação e o trabalho docente, sob a égide neoliberal, tornam-se reféns das intervenções e determinações dos organismos internacionais, pautados no princípio empresarial, visando atender às necessidades do mercado internacional globalizado, sucumbidos pela lógica do capital. Nesse ínterim, existem aqueles sujeitos que apenas pensam e determinam o trabalho a ser realizado pelo docente em sala de aula sem, de fato, ter uma experiência concreta na área educacional, e outros que executam efetivamente $o$ trabalho e conhecem a realidade desse contexto - os professores e demais profissionais que fazem parte da instituição escolar. A respeito das interferências das organizações internacionais, Derisso e Duarte (2017) acrescentam:

[...] a Escola ganhou uma nova caracterização e ficou, em certa medida, refém de intervenções, sobretudo dos organismos internacionais - Banco Mundial e $\mathrm{FMI}^{7}$ - que impõem condições pautadas no princípio empresarial da eficiência e qualidade para a liberação de financiamentos para a educação dos países "em desenvolvimento". Na visão destes organismos internacionais o processo de expansão da escola não acompanhou a qualidade do serviço prestado e isto teria ocorrido pela incompetência dos profissionais [...].

As instituições financeiras internacionais, notadamente o Banco Mundial, norteiam suas "orientações" pela lógica do mercado, abordando a questão educacional num sentido estritamente pragmático, ou seja, o de produzir resultados quantificáveis, propondo soluções eminentemente técnico-racionais [...]

\footnotetext{
7 Fundo Monetário Internacional.
} 
A reforma do Estado visa atender às necessidades do mercado internacional globalizado. O foco principal da orientação dos organismos multilaterais, que no caso da educação brasileira diz mais respeito ao Banco Mundial que é quem financia projetos, é a desoneração do Estado, apontando para a necessidade de estabelecerem novas funções no sentido de reduzir os gastos públicos e de possibilitar o ingresso gradual da iniciativa privada nas atividades até então de competência estatal, para tanto as privatizações e as PPP8. A ideia é que o Estado se desobrigue de manter serviços básicos para a população e que atue somente em áreas tidas, pelo neoliberalismo, como elementares (DERISSO; DUARTE, 2017, 1171-1172).

No que concerne à alienação, a docente Letícia preconiza:

A alienação do trabalho do professor acontece no momento em que ele reproduz a educação, ou seja, aceita o que é estabelecido sem questionar, quando ele (professor) perde o "encantamento" por sua profissão e trabalha simplesmente para sobreviver, corre de uma escola para outra e aceita as condições impostas para se manter. Infelizmente, atualmente eu me encontro nesta situação (LETíCIA - REDE PÚBLICA).

Antunes (1995) discute acerca da forma alienada que o trabalho adquire dentro do capitalismo, em que:

[...] tal como se objetiva na sociedade capitalista, o trabalho é degradado e aviltado. Torna-se estranhado. O que deveria se constituir na finalidade básica do ser social - a sua realização no e pelo trabalho - é pervertido e depauperado. O processo de trabalho se converte em meio de subsistência. A força de trabalho torna-se, como tudo, uma mercadoria, cuja finalidade vem a ser a produção de mercadorias (ANTUNES, 1995, p. 123).

Contribuindo nesta perspectiva, Magalhães e Anes (2016, p. 226) asseveram:

O modelo de trabalho capitalista ao qual nos inserimos na atual conjuntura guarda estas contradições, e nele, em função da sua reprodução e adaptação, tem sido cada vez mais limitada, para não dizer demasiadamente difícil, a possibilidade de desenvolvimento de um trabalho que tem um fim em sim mesmo, como ato de fruição espontânea da vida. Ao contrário,

8 Parcerias Público-Privadas. 
conforme a análise que Manacorda (2007) faz do trabalho em Marx, todo e qualquer tipo de trabalho hoje corresponde necessariamente à produção de mercadoria, gerada a partir da força de trabalho empreendida, e comprada por quem detém o poder econômico. Tornando-se, portanto, trabalho estranhado, em que o sujeito não se reconhece tanto no processo como no produto gerado pelo seu trabalho. E alienado, já que o produto gerado é apropriado por aquele que emprega.

Fazendo uma ligação entre a fala da docente e a afirmação dos autores, fica clara a condição de hegemonia do capital que, visando o lucro, sucumbe $\mathrm{o}$ profissional docente às situações mais degradantes possíveis. Letícia demonstra aceitação da situação, não por conformismo, mas pela falta de autonomia, financeira inclusive, para insurgir-se contra o sistema. É sabido, que com as novas roupagens do capitalismo, o número do desemprego aumenta expressivamente, o que facilita a situação das empresas e até de instituições públicas, por que sabem que se um trabalhador não aceitar as condições impostas, há uma enorme fila atrás dele esperando pela vaga. Esta é mais uma das faces perversas da precarização na educação brasileira. Acerca da nova roupagem do ser/agir docente nos moldes do sistema capitalista, Brito, Prado e Nunes (2017, p. 172-173) preconizam:

As reflexões pontuadas acerca das condições de trabalho docente delineiam um quadro preocupante. As reformas educacionais no contexto de redefinição do papel do Estado apresentam novas formas de organização na estrutura e na gestão das instituições, que traz implicações para a profissão docente.

Num mundo globalizado e marcado pelo capitalismo em expansão, a educação se transformou em uma mercadoria que pode garantir as bases do sistema de acumulação, controle social, competitividade e ajustamento estrutural, por meio de um ensino voltado para o desenvolvimento da capacidade produtiva do homem, adaptável às demandas do capital.

Esse atual paradigma educacional impacta a vida dos professores na medida em que eles passam a assumir novas funções e responsabilidades. Ball (2005) afirma que duas tecnologias importadas do mundo empresarial têm aproximado a educação da lógica do mercado - a performatividade e o 
gerencialismo. Tais tecnologias empregadas na educação apontam para a necessidade de um novo professor e novas práticas pedagógicas.

O novo professor deve ser um profissional competente e eficiente que apresente bom desempenho nas atividades. Esse desempenho tem sido avaliado com base nos resultados obtidos por seus alunos, nas avaliações realizadas em larga escala. Deste modo, o professor é responsável pelo sucesso e/ou insucesso dos alunos.

Piovezan (2017) salienta que a perda do controle sobre o processo de trabalho envolve os docentes numa rede de monitoramento, índices e metas que cerceia a possibilidade de criação e intervenção nas aulas de acordo com as necessidades individuais dos alunos. A perda de autonomia dos docentes é crucial para atender as exigências solicitadas pelo Ministério da Educação e as Secretarias da Educação dos Estados, isto é, a adoção dos currículos, materiais didáticos e avaliações.

Piovezan (2017) ainda estabelece que a nova forma de organização gerencialista da educação, além de controlar todos os processos que determinam o trabalho dos docentes, controla, ainda, todas as propostas de metas que estes profissionais necessitam alcançar nas escolas. Portanto, de acordo com Del Pino, Vieira e Hypolito (2009) os professores são vigiados periodicamente pelo controle burocrático do Estado, de modo que o seu envolvimento com a nova lógica perversa de monitoramento dos resultados acontece quase inconscientemente.

\section{ALGUMAS CONSIDERAÇÕES}

As mudanças ocorridas no mundo do capital, sobretudo nas últimas décadas, promoveram mudanças profundas no mundo do trabalho. Neoliberalismo e a reestruturação produtiva na era da acumulação flexível produziram entre tantos aspectos destrutivos, um monumental desemprego e uma enorme precarização do trabalho. Nota-se um processo análogo nas condições de trabalho dos professores. Muitos são os processos que materializam a precarização da vida do trabalhador. Flexibilização, intensificação, desemprego, desprofissionalização, degradação, sobrecarga, 
cobranças; fragilização, desvalorização, competitividade, perda de autonomia, etc. (SILVA, 2014).

A precarização do trabalho, objeto em investigação, é um fenômeno mundialmente em ascensão. Em países de economias centrais ou periféricas, a precarização provocou uma série de alterações no mundo do trabalho, fragilizando parte dos direitos trabalhistas e sociais conquistados pelos trabalhadores nas últimas décadas. Semelhante a outras categorias de trabalhadores, os docentes vivenciam um processo de degradação da sua força de trabalho, suscitado pelo fenômeno da precarização. A partir dos anos de 1990, foram implementadas no Brasil uma série de políticas neoliberais, a reforma dos direitos trabalhistas e a reforma administrativa do Estado que alterou, por exemplo, a gestão das escolas públicas.

Frente à discussão teórico-conceitual levantada pelo estudo em tela, podemos inferir que nas últimas décadas a educação no Brasil tem sido influenciada pelas reformas de Estado e, consequentemente, as reformas educacionais que visam uma administração gerencial da escola, focada na eficácia e eficiência dos gastos públicos. Em uma conjuntura essencialmente neoliberal, Piovezan (2017) reitera que o país tem seguido tendências educacionais internacionais, que estimulam a racionalização dos gastos com a educação, a formação docente, o arrocho salarial, etc. Tendências estas que reproduzem, eminentemente, os interesses do capital.

Com efeito, os depoimentos das duas docentes em consonância com os achados da literatura, denota a precarização do trabalho docente, materializada, sobretudo, pelo modo em que o trabalho é organizado nos moldes do capitalismo contemporâneo. Esses depoimentos evidenciam que o fenômeno da precarização afeta consideravelmente o seu lócus de trabalho. Não obstante marcado pela flexibilização, intensificação, descumprimento da legislação educacional, a flexibilização das formas contratuais, a perda de autonomia sobre o processo de trabalho, a responsabilização, a competitividade, a desprofissionalização, a degradação, a educação e o labor da classe trabalhadora a serviço do 
capital, o sofrimento psíquico, o adoecimento e alienação dessa categoria profissional.

As conquistas asseguradas constitucionalmente no tocante à valorização docente carecem de um efetivo cumprimento. Nesta perspectiva, "[...] dado que o processo histórico é dinâmico, cabe aos que rejeitam a atual situação engendrar esforços no sentido de transformá-la. [...] tal processo de transformação requer ações no sentido de promover a construção de um modo próprio e mais elaborado de pensar e agir." (FERRETI; SILVA, 2017, p. 401). Assim, esta realidade demanda dos docentes e das associações e sindicatos que os representam um embate ainda mais palpável, no sentido de maximizar a militância em defesa da valorização docente. Espera-se, portanto, que esta investigação contribua tanto para o debate acadêmico como para a luta política e sindical dos trabalhadores contra a exploração capitalista e suas consequências para as condições de vida e trabalho daqueles que precisam vender sua força de trabalho para se reproduzir. Sugere-se novos estudos nessa diração.

\section{REFERÊNCIAS}

ANTUNES, R. Os sentidos do trabalho: ensaio sobre a afirmação e a negação do trabalho. 2. ed. São Paulo: Boitempo, 2009. (Mundo do Trabalho).

ANTUNES, R. Adeus ao Trabalho? Ensaio sobre as metamorfoses e a centralidade do Mundo do Trabalho. São Paulo: Cortez, 1995.

ANTUNES, R; PRAUN, L. A sociedade dos adoecimentos no trabalho. Serv. Soc. Soc., São Paulo, n. 123, p. 407-427, jul./set. 2015

ASSUNÇÃO, A.; OLIVEIRA, D. A. Intensificação do trabalho e saúde dos professores. Educação \& Sociedade, Campinas, v. 30, n. 107, p. 349-372, mai./ago. 2009.

BRASIL. Instituto Nacional de Estudos e Pesquisas Educacionais Anísio Teixeira. Relatório do $2^{\circ}$ Ciclo de Monitoramento das Metas do Plano Nacional de Educação - 2018. - Brasília, DF: Inep, 2018.

BRAVERMAN, H. Trabalho e capital monopolista. Rio de Janeiro: LTC, 1987. 
BRITO, R. dos S.; PRADO, J. R.; NUNES, C. P. As condições de trabalho docente e o pós-estado de bem-estar social. Revista Tempos e Espaços em

Educação, São Cristóvão, Sergipe, Brasil, v. 10, n. 23, p. 165-174, set./dez.

2017.

DERISSO, J. L.; DUARTE, R. de C. Crítica ao ideário neoliberal na educação: precarização e descaracterização da escola pública paulista. Rev. HISTEDBR On-line, Campinas, v.17, n.4 [74], p.1169-1185, out./dez. 2017.

DEL PINO, M. A. B.; VIEIRA, J. S.; HYPOLITO, A. M. Trabalho docente, controle e intensificação: câmeras, novo gerencialismo e práticas de governo. In: FIDALGO, F.; DERISSO, José Luis; DUARTE, Rita de Cássia. Crítica ao ideário neoliberal na educação: precarização e descaracterização da escola pública paulista. Rev. HISTEDBR On-line, Campinas, v.17, n.4 [74], p.1169-1185, out./dez. 2017.

DRUCK, G. Trabalho, precarização e resistências: novos e velhos desafios? Cadernos CRH, Salvador, v. 24, p. 37-57, 2011.

FERRETI, C. J.; SILVA, M. R. Reforma do ensino médio no contexto da medida provisória n 746/2016: Estado, currículo e disputas por hegemonia. Educ.

Soc., Campinas, v. 38, n. 139, p. 385-404, abr./jun. 2017.

FRANCO, T.; DRUCK, G.; SELIGMANN-SILVA, E. As novas relações de trabalho, o desgaste mental do trabalhador e os transtornos mentais no trabalho precarizado. Revista Brasileira de Saúde Ocupacional, São Paulo, v. 35, n. 122, p. 229-248, jul./dez. 2010.

FRIGOTTO, G. A educação e a crise do capitalismo real. São Paulo: Cortez, 1995.

MAGALHÃES, S. M. O.; ANES, R. R. M. O trabalho docente na contemporaneidade: da resignação à emancipação. Práxis Educacional. Vitória da Conquista. V. 12, n. 23. p. 223-249. Set./dez. 2016.

MARX, K. O Capital: crítica da economia política (V.1). Trad. Regis Barbosa e Flávio Kothe. São Paulo: Nova Cultural, 1988.

MATIAS, M. C. M.; ABIB, J. A. D. Sociedade em transformação: estudo das relações entre trabalho, saúde e subjetividade. Londrina: EDUEL, 2007. 316 p.

\section{MAZZINI, M. do C. C. A precarização do trabalho das professoras da rede} municipal de educação de Marília/SP. 2017. 144 f. Dissertação (Mestrado em Educação) - Programa de Pós-Graduação em Educação da Faculdade de Filosofia e Ciências, da Universidade Estadual Paulista, Marília, 2017. 
MOURA, J. da S.; RIBEIRO, J. C. de O. A.; CASTRO NETA, A. A. NUNES, C. P. A precarização do trabalho docente e o adoecimento mental no contexto neoliberal. RPD, Uberaba-MG, v.19, n.40, p.01-17, jan./abr. 2019, ISSN 15190919.

NOGUEIRA, S. T. O.; BRASIL, K. T. R. O lugar do reconhecimento no trabalho docente. Revista EXITUS. Volume 03. Número 02. Jul/Dez. 2013. P. 93-107.

NOZAKI, H. T.; ANDRADE, R. A. Costa. Políticas educacionais da década de 1990 e a formação do trabalhador de novo tipo. In: KASSAR, Mônica de Carvalho Magalhães (Orgs.). Diálogos com a diversidade. Sentidos da inclusão. Campinas: Mercado das Letras, 2011.

PERONI, V. M. V. A privatização do público: implicações para a democratização da educação. In: PERONI, V. M. V. (Org.) Redefinições das fronteiras entre o público e o privado: implicações para a democratização da educação. Brasília: Liber Livro, 2013, p. 9-32.

PERONI, V. M. V. Implicações da relação público-privado para a democratização da educação no Brasil. In: PERONI, V. M. V. (Org.). Diálogos sobre as redefinições no papel do Estado e nas fronteiras entre público e privado na educação. São Leopoldo, Oikos, 2015, p. 15-34.

PIOVEZAN, P. R. As políticas educacionais e a precarização do trabalho docente no Brasil e em Portugal. 2017. 225 f. Tese (Doutorado em Educação) - Programa de Pós-Graduação em Educação da Faculdade de Filosofia e Ciências da Universidade Estadual Paulista, Marília, 2017.

RODRIGUES, D. V. O “ajuste" neoliberal e a precarização do trabalho docente no governo José Serra em São Paulo. 2017. 148 f. Dissertação (Mestrado em Educação) - Programa de Pós-Graduação em Educação da Universidade Estadual de Campinas, Campinas, 2017.

ROSENFIELD, C. L. Trabalho decente e precarização. Tempo Social, São Paulo, v. 23, n.01, p. 247-268, jun. 2011.

SANTOS, A. F. T. Pedagogia do mercado: neoliberalismo, trabalho e educação no século XXI. Rio de Janeiro, Ibis Libris, 2012.

SANTOS, D. A. dos. Contribuições da psicologia histórico-cultural para a compressão do adoecimento e sofrimento psíquico de professores. 2014. 195f. Dissertação (Mestrado em Psicologia) - Programa de Pós-Graduação em Psicologia, Universidade Estadual de Maringá, Maringá, 2014.

SILVA, D. As políticas neoliberais e a precarização do trabalho docente em uma microrealidade de duas escolas mantidas pelo estado em Porto Velho Ro. 2014. 97 f. Dissertação (Mestrado em Educação) - Programa de Pós- 
Graduação em Educação do Núcleo de Ciências Humanas da Universidade Federal de Rondônia, Porto Velho, 2014.

Recebido em: 10 de setembro de 2019 Aprovado em: 13 de fevereiro de 2020 (c) (i) (8) 